\title{
Relaxation Technique and Premenstual Syndrome: A Psychophysiological Study.
}

\author{
Dr. Veena jasuja, Dr. Samir mendpara, Ms. Geetanjali Purohit, Dr.B.M.Palan. \\ Dept. of Physiology, S B K S medical college and Research centre, Piparia, Vadodara.
}

\begin{abstract}
Abstact: The aims of this study were to validate the efficacy of progressive muscular relaxation technique to relieve symptoms of premenstrual syndrome and to evaluate cardiovascular and respiratory parameters that may serve as objective measures of the efficacy of progressive muscular relaxation. A total 90 participants were randomly assigned to group A an experimental group, group B as control group, group $C$ as absolute control group.

Physiological parameters included in this study were pulse rate, Systolic blood pressure, Diastolic blood pressure, Respiratory rate, Peak expiratory flow rate, O2 saturation. All the parameters were recorded at beginning and at end after intervention. PMR technique was used in experimental group only. For one month group A was given PMR. Progressive muscular relaxation showed significant possible benefits in terms of decrease in pulse rate, $S B P$ and $R R$. PEFR increased and $\mathrm{SPO}_{2}$ did not show any change.
\end{abstract}

Key worlds: progressive muscular relaxation, premenstrual syndrome, relaxation technique.

Submitted date 12 June 2013

Accepted Date: 17 June 2013

\section{Introduction}

For many centuries the menstrual cycle has held negative connotations for women. There has been advancement of knowledge with the advent of understanding that female sex hormones underlie the menstrual cycle and mood disorders related to menstruation are significant problem for some women. American psychiatric association (APA) explicitly acknowledges in the Diagnostic and statistical Manual for mental disorders (DSM -IV-TR) that up to $70 \%$ of women are affected by at least mild symptoms of premenstrual syndrome. ${ }^{(1)}$

Other important clinical correlate of premenstrual syndrome is life stress. PMS in its severe form affects $2.5 \%$ of women of reproductive age; in more mild form it is estimated to affect approximately $40 \%$ of women in this age group. ${ }^{(2)}$ Several studies have shown an association between premenstrual menstrual syndrome and stress full life events, including past sexual abuse in up to $40 \%$ of women. Premenstrual mood disturbances have also been associated with high levels of day to day stress. ${ }^{(3)}$

\section{Place Of Study}

This study was done at the department of physiology, S. B. K. S. Medical College. All the participants in this study were students of S. B. K. S. Medical College. Age group was 18 to 40 years.

STUDY DESIGN:

After getting clearance certificate from ethical comity of medical college, we started our work on this study. All the participants were interviewed and those who met with inclusion criteria were invited for this study.

\section{- INCLUSION CRITERIA:}

- $\quad$ Age group of 18 to 45 years.

- $\quad$ Participants having one symptom either an affective or a somatic symptom of premenstrual syndrome.

- $\quad$ Symptoms restricted to luteal phase of menstrual cycle only.

- $\quad$ Participants who gave informed consent after detail information of study

All participants were first given the detailed information and then written informed consent was taken. A detailed history was taken according to Base line evaluation Performa and general and physical examination were done.

Now participants were randomly divided into 3 groups. Sample size of each group was 30 .

GROUP A is a PMR group which was given progressive muscular relaxation therapy as an intervention. Group B was not given PMR but had contact with them twice a week same like group A. Group C is an absolute control group. With this group there was no contact during 3 months of study. 


\section{FIRST GROUP A: EXPERIMENTAL GROUP (30 participants)}

(PROGRESSIVE MUSCULAR RELAXATION GROUP):

First group was experimental group who was given relaxation therapy by recorded instruction of progressive muscular relaxation in voice of Dr B.M. Palan. Relaxation session was given twice a week for a month. All participants were given recorded version of PMR to practice relaxation at home. All parameters were recorded at the beginning of study. Follow up was done after three month, again all the parameters were recorded.

\section{SECOND GROUP B: CONTROL GROUP (30 participants)}

Firstly as per protocol, all the participants were given detailed information regarding my study and same protocol for history and examination was followed All the parameters were recorded same as it was done for the first group. Participants of this group also, visited twice a week, but here no intervention in form of relaxation therapy was given. They just visited to department of physiology twice a week for an informal meet. Follow up was done at the end of 3 months.

\section{THIRD GROUP C: ABSOLUTE CONTROL GROUP (30 participants)}

For this group, all the parameters were recorded same as it was done for two groups. But unlike other two groups there was no contact for 3 months of study. The study included total 90 participants who were similar with respect to Age, Sex, and educational level.

Statistical analysis - All raw data were entered into Microsoft Excel spread sheet and analyzed. Parametric data were analyzed using students t test both paired and unpaired.

\section{Results}

Results are summarized in tabulated form in table no. 1 to 6 and same is represented in Figures no 1 to 6.

TABLE NO. 1: PULSE RATE (BEATS/MINUTE) IN THREE DIFFERENT GROUPS BEFORE AND AFTER INTERVENTION

\begin{tabular}{|l|l|l|l|l|l|l|}
\hline \multicolumn{2}{|l|}{} & \multicolumn{2}{|l|}{ GROUP A } & \multicolumn{2}{l|}{ GROUP B } & \multicolumn{2}{l|}{ GROUP C } \\
\cline { 2 - 7 } & BEFORE & AFTER & BEFORE & AFTER & BEFORE & AFTER \\
\hline MEAN & 92.4333 & 64.4 & 70.56667 & 65.4 & 69.06667 & 68.4666 \\
\hline SD & 7.708854 & 4.20672 & 6.631603 & 4.3358 & 5.551846 & 4.74429 \\
\hline $\mathrm{t}$ value & 18.8756 & 4.7071 & & 1.2732 & \\
\& & $<0.001$ & $<0.001$ & & NS & \\
$\mathrm{p}$ value & & & & & \\
\hline
\end{tabular}

Group A shows highly significant change $(\mathrm{p}<0.001)$, group B also shows significant change. Group C shows no significant change

FIGURE 1: PULSE RATE IN 3 DIFFERENT GROUPS BEFORE AND AFTER

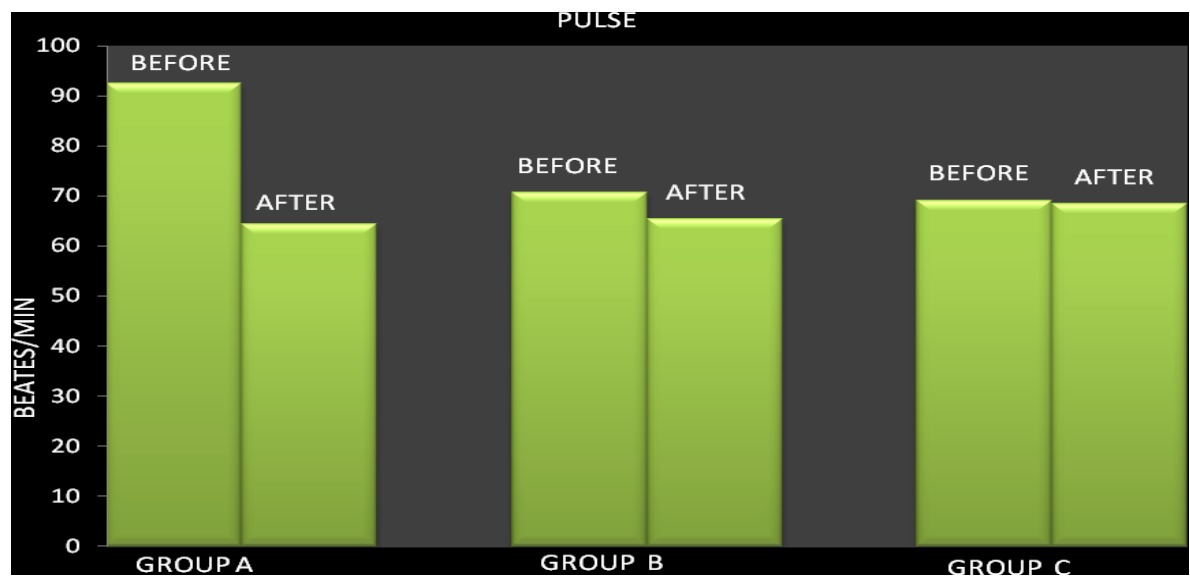

\section{INTERVENTION:}


TABLE NO. 2: SYSTOLIC BLOODPRESSURE (MM OF HG) IN THREE DIFFERENT GROUPS BEFORE AND AFTER INTERVENTION

\begin{tabular}{|c|c|c|c|c|c|c|}
\hline & \multicolumn{2}{|l|}{$\begin{array}{l}\text { GROUP } \\
\text { A }\end{array}$} & \multicolumn{2}{|l|}{$\begin{array}{l}\text { GROUP } \\
\text { B }\end{array}$} & \multicolumn{2}{|l|}{$\begin{array}{l}\text { GROUP } \\
\mathrm{C}\end{array}$} \\
\hline & BEFORE & AFTER & BEFORE & AFTER & BEFORE & AFTER \\
\hline MEAN & 108.53 & 101.4 & 108.66 & 106.2 & 109.33 & 109.06 \\
\hline SD & 7.57 & 4.93 & 6.89 & 5.12 & 7.11 & 7.31 \\
\hline $\begin{array}{l}\text { t value } \\
\& \\
\text { p value }\end{array}$ & \multicolumn{2}{|l|}{$\begin{array}{l}9.54 \\
<0.001\end{array}$} & \multicolumn{2}{|l|}{$\begin{array}{l}0.29 \\
\text { NS }\end{array}$} & \multicolumn{2}{|l|}{$\begin{array}{l}1.0 \\
\mathrm{NS}\end{array}$} \\
\hline
\end{tabular}

FIGURE 2: SYSTOLIC BLOOD PRESSURE IN 3 DIFFERENT GROUPS BEFORE AND AFTER INTERVENTION.

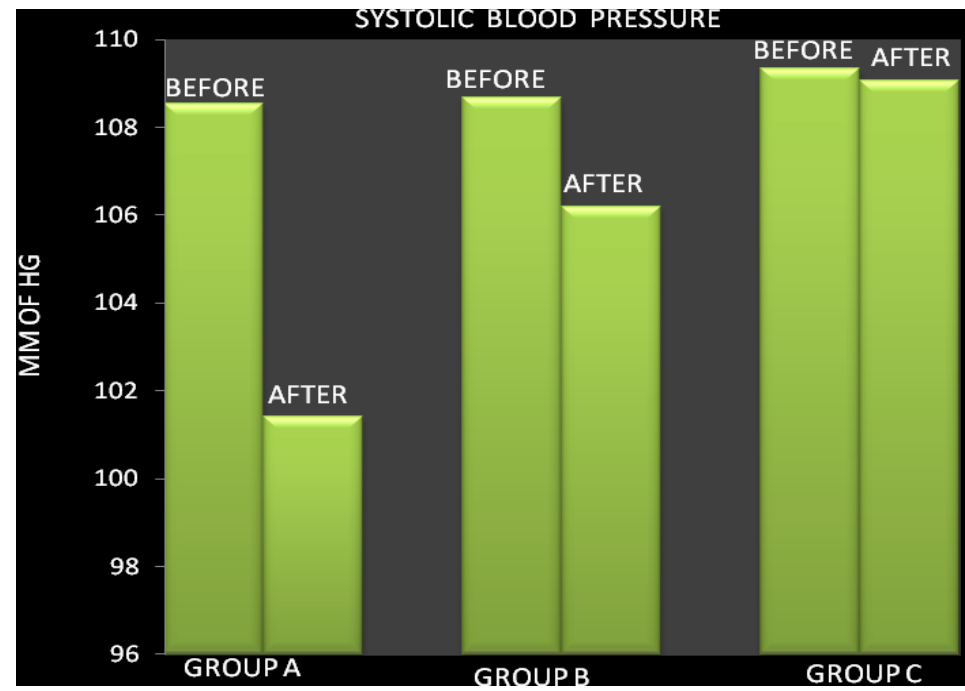

Group A shows highly significant change ( $\mathrm{p}<.001)$, group B and C do not show any statistically significant change.

TABLE NO. 3: DIASTOLIC BLOOD PRESSURE (MM OF HG) IN THREE DIFFERENT GROUPS BEFORE AND AFTER INTERVENTION.

\begin{tabular}{|l|l|l|l|l|l|l|}
\hline & \multicolumn{3}{|l|}{ GROUP A } & \multicolumn{2}{l|}{ GROUP B } & \multicolumn{2}{l|}{ GROUP C } \\
\hline & BEFORE & AFTER & BEFORE & AFTER & BEFORE & AFTER \\
\hline MEAN & 66.73 & 65.73 & 66.33 & 65.73 & 67.46 & 67.8 \\
\hline SD & 8.02 & 7.66 & 4.72 & 4.68 & 6.00 & 5.95 \\
\hline $\begin{array}{l}\mathrm{t} \text { value } \& \\
\text { pvalue }\end{array}$ & 1.54 & NS & 1.72 & -0.59 & \\
\hline
\end{tabular}

FIGURE 3: DIASTOLIC BLOOD PRESSURE IN THREE DIFFERENT GROUPS.

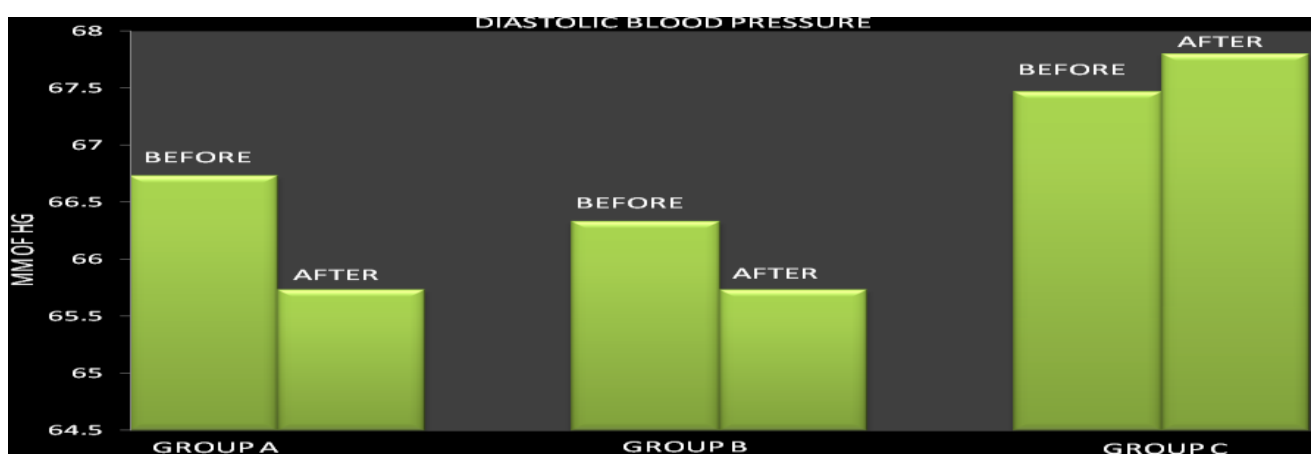

Group A, group B and group C do not show statistically significant change. $(\mathrm{p}<0.10)$ 
Relaxation Technique And Premenstual Syndrome: A Psychophysiological Study.

TABLE NO. 4: RESPIRATORY RATE (BREATHES/MINUTE) IN THREE DIFFERENT GROUPS BEFORE AND AFTER INTERVANTION.

\begin{tabular}{|l|l|l|l|l|l|l|}
\hline & \multicolumn{3}{|l|}{ GROUP A } & \multicolumn{2}{l|}{ GROUP B } & GROUP C \\
\hline & BEFORE & AFTER & BEFORE & AFTER & BEFORE & AFTER \\
\hline MEAN & 13.8 & 11.2 & 14 & 13 & 13.8 & 13.6333 \\
\hline SD & 2.310396 & 1.5844 & 2.034191 & 1.9826 & 1.769473 & 1.51960 \\
\hline $\mathrm{t}$ value \& & 9.4975 & 7.7371 & 1.8992 & \\
p value & $<0.001$ & $<0.001$ & NS & \\
\hline
\end{tabular}

FIGURE 4: RESPIRATORY RATE IN THREE DIFFERENT GROUPS.

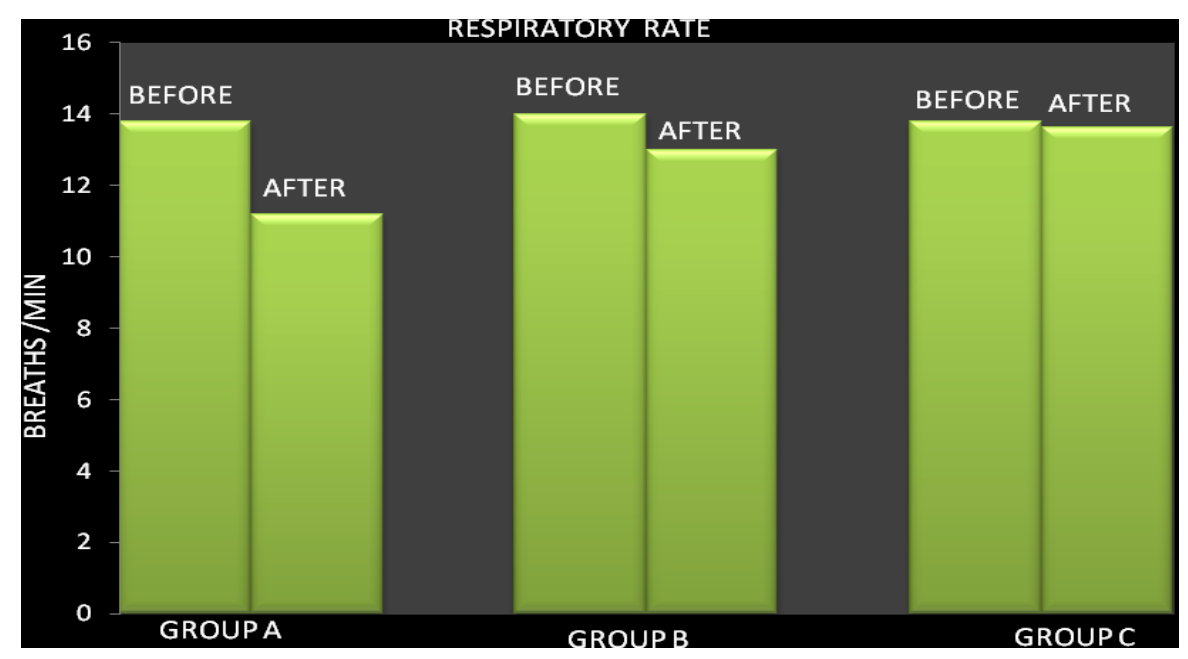

Group A shows highly significant change ( $\mathrm{P}<.001)$. Group B also shows highly significant change ( $<<.001)$, But less than A. Group $\mathrm{C}$ does not show any change.

TABLE NO 5: $\mathrm{SPO}_{2}\left(\%\right.$ OF $\mathrm{O}_{2}$ SATURATION) IN THREE DIFFERENT GROUPS BEFORE AND AFTER INTERVENTION.

\begin{tabular}{|l|l|l|l|l|l|l|}
\hline & \multicolumn{3}{|l|}{ GROUP A } & \multicolumn{2}{l|}{ GROUP B } & \multicolumn{2}{l|}{ GROUP C } \\
\cline { 2 - 7 } & BEFORE & AFTER & BEFORE & AFTER & BEFORE & AFTER \\
\hline MEAN & 98.6333 & 98.9 & 98.63333 & 98.7333 & 98.4667 & 98.5 \\
\hline SD & 0.556053 & 0.5477 & 0.556053 & 0.44977 & 0.681445 & 0.6297 \\
\hline $\begin{array}{l}\text { t value } \\
\& \\
\text { p value }\end{array}$ & -2.21122 & -1.3605 & & 0 & \\
\hline
\end{tabular}

FIGURE 5: $\mathrm{SPO}_{2}$ IN THREE DIFFERENT GROUPS:

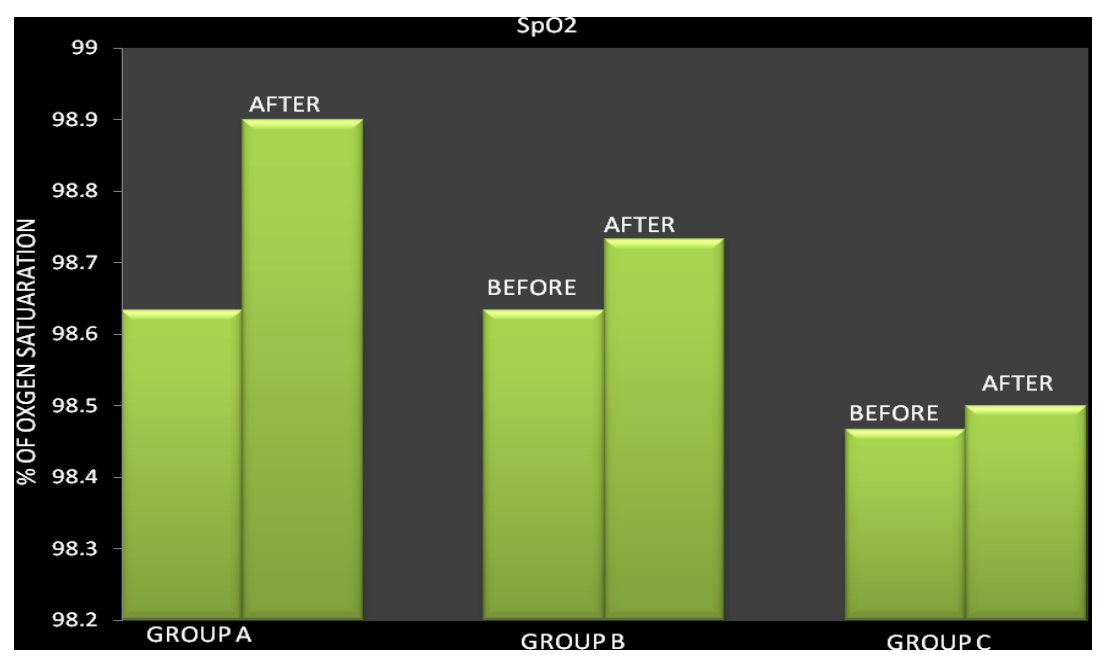

Group A shows statistically significant $(\mathrm{p}<0.05)$ increase after relaxation. Group B and group C do not show statistically significant change in $\mathrm{SPO}_{2}$. $(\mathrm{p}<0.10)$ 
Relaxation Technique And Premenstual Syndrome: A Psychophysiological Study.

TABLE NO 6: PEAK EXPIRATORY FLOW RATE (LITERS/ MIN) IN THREE DIFFERENT GROUPS: BEFORE AND AFTER INTERVENTION.

\begin{tabular}{|c|c|c|c|c|c|c|}
\hline & \multicolumn{2}{|c|}{ GROUP A } & \multicolumn{2}{|c|}{ GROUP B } & \multicolumn{2}{|l|}{ GROUP C } \\
\hline & BEFORE & AFTER & BEFORE & AFTER & BEFORE & AFTER \\
\hline MEAN & 349 & 389.5 & 348 & 357 & 384.333 & 357.666 \\
\hline SD & 31.00056 & 14.163 & 24.12611 & 24.795 & 23.29471 & 22.9967 \\
\hline $\begin{array}{l}T \\
\text { value } \\
\& \\
\text { p value }\end{array}$ & $\begin{array}{l}9.4388 \\
0.05\end{array}$ & & $\begin{array}{l}1.7983 \\
\text { NS }\end{array}$ & & $\begin{array}{l}1.4094 \\
\text { NS }\end{array}$ & \\
\hline
\end{tabular}

FIGURE 6: PEAK EXPIRATORY FLOW RATE IN THREE DIFFERENT GROUPS.

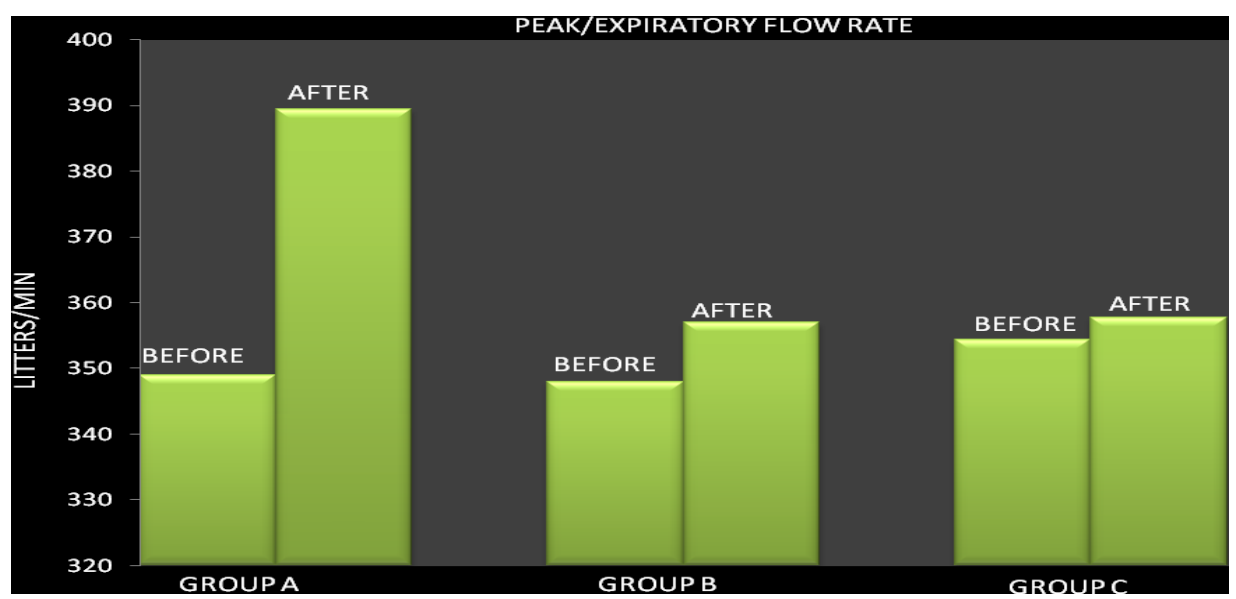

Group A shows significant increase after relaxation $(\mathrm{p}<0.001)$. Group B and group C do not show significant change $(\mathrm{p}<0.1$

\section{Discussion}

Premenstrual syndrome (PMS) is a condition of recurrent physical and psychological symptoms occurring in cyclic fashion during luteal phase of menstrual cycle of women. Every woman during her reproductive age starting from menarche at the age of 12 to 13 years to the age of menopause experiences these cyclic changes. Most of the women experience either physical or psychological symptom in mild to moderate from during her reproductive age. ${ }^{(4)}$ Many different etiologies have been proposed for the symptoms of PMS; none have been definitely established as a dominant cause. Possible influences include hormonal imbalance, specifically progesterone level during the luteal phase of the cycle; abnormal neurotransmitter response to ovarian signaling; disordered aldosterone function leading to sodium and water retention; abnormal hypothalamic-pituitary -adrenal (HPA) axis function leading to deficient adrenal hormone secretion; nutritional deficiency including magnesium, pyridoxine; carbohydrate intolerance; environmental factors including stress. No single etiology explains every case, so it is assumed that this disorder is multifactorial in origin. ${ }^{(5-9)}$

Increased sympathetic activity seen as a result of stress causes an increase in the heart rate, systolic blood pressure and diastolic blood pressure. The muscle tone, skin conductance and RR also increased as a result of it. Predominance of parasympathetic activity has the effects opposite to it.

The relaxation response reduces the sympathetic tone and causes reduction in the pulse and blood pressure; and has proved its role as an useful adjuvant therapy for hypertension.

The PMR lowered pulse rate and systolic blood pressure in group A which was highly significant statistically $(\mathrm{P}<.001)$. These findings collaborate with the observation of jyoti dvivedi et al; who studied the effect of 61 Point relaxation technique on PMS and control group. ${ }^{(10)}$ The same was reported by Goodale et al, who have studied different forms of relaxation response in their studies. ${ }^{(11)}$

In present study we did not find any statistically significant change in value of DBP in all three groups. Jyoti et al reported in their study that basal diastolic blood pressure in the subjects of PMS group was significantly higher than the control and it also showed highly significant decrease aster intervention in form of 61PR. ${ }^{(10)}$

Respiration slows down during the course of relaxation. Relaxation as we know diminishes the activity of sympathetic nervous system. So sympathetic input to respiratory system decreases and parasympathetic input to bronchioles increases.

In present study the PMR group A showed highly significant change statistically in RR. This finding 
also supports the observation of Goodale et al and Jyoti et al also reported same in their studies. ${ }^{(10-11)}$

Airflow and lung diffusing capacity varied over the menstrual cycle with peak levels during menstrual phase of menstrual cycle that subsequently declined to nadir in early luteal phase. Another respiratory parameters included in our study were SPO2 and PEFR. Variable SPO2 did not show any statistically significant change in all three study groups.

PEFR in group A (PMR group) showed statistically highly significant change. Group B showed change but not significant and group $\mathrm{C}$ too did not show any change.

Farha et al reported that women with asthma experience cyclic changes in airflow as well as gas transfer and membrane diffusing capacity supportive of hormonal effect on lung function. ${ }^{(12)}$

Furthermore, during the luteal phase there is evidence of increased physiologic responsivity to stress as measured by heart rate, blood pressure, adrenocortical activity, and urinary (D6) excretion of epinephrine and norepinephrine. Other studies however, have shown no changes in heart rate and respiratory rate or adrenocortical responsivity throughout the menstrual cycle. ${ }^{(13-16)}$

Relaxation training is a useful adjuvant therapy for PMS, but there is limited research evidence to support its use in isolation. Exercise has been more rigorously studied .It is unclear if exercise induced symptom improvement is a result of physiological or psychological changes.

Because many questions regarding the neuroendocrinologic mechanisms involved in PMS remain unanswered, one can only speculate about the physiological mechanisms by which regular practice of relaxation may decrease the severity of premenstrual symptoms.

One mechanism could involve neither changes in norepinephrine status. There is evidence that women have increased norepinepherine receptor sensivity during the few days before menstrual cycle. Such a change in norepinephine sensitivity might explain the commonly experienced premenstrual increase in aggression (i.e. hostility, irritability, and anger), and anxiety because both of these moods / behaviors are mediated, at least in part through the noradrenergic system. Because regular elicitation of relaxation therapy results in deceased norepinephrine responsivity in patients characterized by abnormally high premenstrual noradrenergic activity.

Gender differences in depression, has been discussed. Considering that the findings about the association between PMS and depression are also of significance. It has been suggested that reproductive hormones might contribute to the increased risk in women of suffering from depression compared to men

Uriel Halbrih, et al reported relatively high prevalence of women reporting both PMS and major depression, sustains the hypothesis of the contribution of reproductive hormones and thus might be an explanatory factor for the higher prevalence of depression in women compared to men. ${ }^{(17)}$

\section{References}

[1]. American Psychiatric Association. Diagnostic and statistical manual of mental disorders-DSM-I4. Washington DC: American Psychiatric Association; 1994.

[2]. Mortola J: Premenstrual syndrome- pathophysiologic considerations. N Engl J Med 338:256-257, 1998

[3]. Woods NF, Most A, Lohgenecker GD . Major life events, daily stressors, and premenstrual syndromes. Nurse Res 1985;34:263-7.

[4]. Reid R: Premenstrual syndrome. N Engl J Med 324:1208-1210, 1991

[5]. Snyderman R, Weil AT: Integrative medicine: bringing medicineback to its roots. Arch Int Med162:395-397, 2002

[6]. Bell IR, Caspi O, Schwartz GE, et al: Integrative medicine andsystemic outcomes research. Arch Med 162:133-140, 2002

[7]. Chrousos GP, Torpy DJ, Gold PW: Interactions between the hypothalamic-pituitary-adrenal axis and the female reproductivesystem: implications. Ann Intern Med 129:229-240, 1998

[8]. Mortola J: Premenstrual syndrome-pathophysiologic considerations. N Engl J Med 338:256-257, 1998

[9]. Singh B, Berman B, Simpson R, et al: Incidence of premenstrual syndrome and remedy usage: a national probability sample study. Altern Ther Health Med 4:75-79, 1998

[10]. Jyoti dvivedi et Effect of 61- Points relaxation technique on stress parameters in premenstrual syndrome, Indian J Physiol Pharmacol 2008; 52 (1) : 69-76 654

[11]. Goodale IL, Domar AD, Benson H, Alleviation of premenstrual syndrome symptoms with the relaxation response. Obstet Gynecol. 1990 Apr;75(4):649-55.

[12]. Hastrup JL, Light KC. Sex differences I cardiovascular stress responses: Modulation as a function of menstrual cycle phases. Psychosom Res 1984;28:475-83.

[13]. Siegel J, Johnson J, Sarson I.Life changes and menstrual discomfort. J Human strss 1979;5:41-6.

[14]. Woods NF,Devy GK,Most A. Major life evetrnts and premenstrual symptoms.J humans stress.1982;8:23-31

[15]. Woods NF,Most A,LOngenencker GD. Major life events, daily stressors, and perimenstrual synmptoms.Nurs Res 1985;11:579-90.

[16]. Little BC, Zahn TP. Changes in mood and autonomic functioning during the menstrual cycle.Psycophysiology1974;11:579-90.

[17]. Uriel Halbreich, Linda S. Kahn, Atypical depression, somatic depression and anxious depression in women: Are they genderpreferred phenotypes? Journal of Affective Disorders Volume 102, Issues 1-3, September 2007, Pages 245-258.

[18]. Kirkby RJ: Changes in premenstrual symptoms and irrational thinking following cognitive-behavioral skills training. J Consult Clin Psychol 62:1026-1032, 1994

[19]. Morse CA, Dennerstein L, Farrell E, et al: A comparison of hormone therapy, coping skills training, and relaxation for the relefof premenstrual syndrome. Behav Med 14:469-489,1991. 